\title{
Concentrations and distribution of synthetic musks and siloxanes in sewage sludge of wastewater treatment plants in China
}

\author{
Nannan Liu, Yali Shi, Wenhui Li, Lin Xu, Yaqi Cai * \\ State Key Laboratory of Environmental Chemistry and Ecotoxicology, Research Center for Eco-Environmental Science, Chinese Academy of Sciences, Beijing 100085, China
}

\section{H I G H L I G H T S}

- High levels and detection frequencies of SMs and siloxanes were found in sludge.

- SM levels were correlated with the TOC of the sludge and serving population of WWTPs.

- Cyclic siloxane levels had a positive correlation with the treatment capacity of WWTPs.

- Linear siloxane concentrations had correlation with the TOC of the sludge in WWTPs.

- When using treated sewage sludge as bio-solids, negligible effect was observed.

\section{A R T I C L E I N F O}

\section{Article history:}

Received 21 August 2013

Received in revised form 14 December 2013

Accepted 30 December 2013

Available online 21 January 2014

\section{Keywords:}

Synthetic musks

Cyclic siloxane

Linear siloxanes

Sludge

Bio-solids

Risk quotient

\begin{abstract}
A B S T R A C T
In this study, we assessed the occurrence and distribution patterns of seven synthetic musks (SMs) and 17 siloxanes in anaerobic digested sludge samples collected at the dewatering process from 42 wastewater treatment plants (WWTPs) in China. SMs in sludge from different WWTPs exhibited similar composition profiles, and their total concentrations ranged from $47.3 \mathrm{ng} / \mathrm{g}$ to $68.2 \mu \mathrm{g} / \mathrm{g}$ dry weight (dw). On average, galaxolide (HHCB, 63.8\%) and tonalide (AHTN, 31.7\%) accounted for 95.5\% of $\sum$ SMs. The total concentrations of cyclic siloxanes ranged from $<$ LOQ (limit of quantitation) to $36.1 \mu \mathrm{g} / \mathrm{g} \mathrm{dw}$ (mean: $1.98 \mu \mathrm{g} / \mathrm{g}$ ), while from $<\mathrm{LOQ}$ to $13.2 \mu \mathrm{g} / \mathrm{g} \mathrm{dw}$ (mean: $0.937 \mu \mathrm{g} / \mathrm{g}$ ) for linear siloxanes. On average, cyclic siloxanes accounted for $68 \%$ of the total siloxanes. High concentrations and detection frequencies of SMs and siloxanes in sewage sludge indicated that both of them were widely used in China. Among the sludge samples from 42 WWTPs, the concentrations of both $\sum$ SMs and $\sum$ siloxanes had considerable variations. We investigated the influence of potential factors (wastewater and sludge characteristics, the treatment capacity, serving population, and the treatment techniques of WWTPs) on the levels of target compounds in sludge, and found that SMs were significantly $(p<0.05)$ correlated with the total organic carbon (TOC) of the sludge and the serving population of WWTP. There were also strong correlations $(p<0.05)$ between the treatment capacity of WWTPs and cyclic siloxanes, as well as between the TOC of the sludge and linear siloxanes. In addition, the ecological risks of SMs and siloxanes in sewage sludge addressed to land application were assessed, which suggested that there was a low risk to the soil environment.
\end{abstract}

Crown Copyright @ 2014 Published by Elsevier B.V. All rights reserved.

\section{Introduction}

As the low-cost substitutes for natural musks, synthetic musks (SMs) have been widely used as fragrances in most of detergents, cleaning agents and various cosmetic products due to their typical musky scents and fixative properties (Lu et al., 2011a). With a high production rate of SMs (8000 tons/year) in the last 5 years, China has been a major producer of musk compounds in the world (Guo et al., 2012). SMs can be mainly divided into nitro musks (NMs) and polycyclic musks (PCMs) according to their chemical structures. Musk xylene (MX) and musk ketone (MK) are the main NMs, while galaxolide

\footnotetext{
* Corresponding author. Tel./fax: + 861062849182 .

E-mail address: caiyaqi@rcees.ac.cn (Y. Cai).
}

(HHCB) and tonalide (AHTN) are the most commonly used PCMs. It was estimated that HHCB and AHTN represented about $95 \%$ of the market share in Europe for all PCMs (Upadhyay et al., 2011). Since the late 1980s, the production of NMs has been dramatically decreased and even banned in some countries due to their potential toxicity to human health and environment (Nakata et al., 2007). Both HHCB and AHTN have been featured as high production volume (HPV) chemicals by the US Environmental Protection Agency (EPA) and the 2007 OECD (Organization for Economic Co-operation and Development). More than 1000 tons/year of these two chemicals are produced or imported in at least one country/region among the OECD members (Kubwabo et al., 2012; Lu et al., 2011b). Due to their widespread use and low rates of degradation, SMs have been found not only in various environmental matrices (air, water and sediment, etc.), but also in many biota 
even in human milk, blood, fat and adipose tissue (Guo et al., 2010; Moon et al., 2012).

Siloxane, another class of HPV chemicals, is used not only in a broad range of consumer products, but also in industrial products, such as automotive polishes, fuel additives and anti-foaming agents due to their special properties such as low surface tension, physiologic inertness, high thermal stability and smooth texture (Companioni-Damas et al., 2012; Sanchis et al., 2013; Xu et al., 2012b). The annual production of octamethylcyclotetrasiloxane (D4) is about 45-227 thousand tons, indicating a great potential for widespread presence of siloxanes in the environment (Horii and Kannan, 2008). Several studies have reported the occurrence of siloxanes in various environmental and biota matrices (Borga et al., 2012; Hanssen et al., 2013; Krogseth et al., 2013). Owing to their potential toxic effects on organisms, SMs and siloxanes were of concern from their ubiquitous environmental occurrence (Parrott et al., 2012; Schnell et al., 2009).

As their widespread use in daily life, SMs and siloxanes are likely to be discharged into sewage systems with the applied "rinse-off" products (Whelan, 2013). For example, the total mass of siloxanes draining into wastewater was estimated at 17,000 tons/year in the USA (Dewil et al., 2006). Moreover, SMs and siloxanes tend to be preferentially adsorbed onto sludge in WWTPs because of their poor water solubility and high octanol-water partition coefficients (Hanssen et al., 2013; Heberer, 2003). Due to the low degradability, considerable amounts of SMs and siloxanes remain in sludge rather than complete elimination after treatment with common technologies in WWTPs (Horii et al., 2007; Parker et al., 1999; Xu et al., 2012a). Previous studies showed that the absorption of HHCB and AHTN onto sludge contributed 50\%$90 \%$ of the removal efficiencies, while $77 \%$ for D4 and $73.2 \%-94 \%$ for decamethylcyclopentasiloxane (D5) (Brooke et al., 2009; Guo et al., 2010; Sanchis et al., 2013). Moreover, the excess sludge is often applied as fertilizer in agriculture, which could lead to the potential dispersal of pollutants to soils, and then transferred to different environmental compartments (air and surface water, for instance) and biota (Arvaniti et al., 2012; Zeng et al., 2005). The annual amount of WWTP sludge is estimated to be up to $1.3 \times 10^{6}$ tons $\mathrm{dw}$, which keeps increasing at a rate of approximately 10\% per year in China (Lu et al., 2012). Sewage sludge is one important transitional sink and a reservoir that should be of special concern to investigate the level, distribution, fate and release of siloxanes. So it is essential to assess the occurrences, distribution, and ecological risks of siloxanes in the sewage sludge on a large scale in China. However, to the best of our knowledge, relevant studies are scarce.

Here we investigated the levels and composition profiles of SMs and siloxanes in sewage sludge from 42 WWTPs collected from 23 representative cities in China. Then the potential factors affecting their levels in sewage sludge were assessed. Finally, we evaluated the ecological risks of SMs and siloxanes when sewage sludge was addressed to land application.

\section{Materials and methods}

\subsection{Sample collection}

The sampling map and sites are shown in Fig. 1. From October 2010 to March 2011, a total of 42 sewage sludge samples were collected from different WWTPs in 23 cities, most of which are located in relatively developed provinces in China. Freshly anaerobic digested sludge samples were collected at the dewatering process, packed in aluminum foil and sealed in polypropylene bags. The field blanks were also collected during the sampling procedure. Subsequently, the samples and the filed blanks were freeze-dried, homogenized and finally stored at $-20{ }^{\circ} \mathrm{C}$ prior to further analysis. Detailed information of the investigated WWTPs is given in Table 1, regarding the serving population, treatment capacity, treatment technique, and sources of effluents.

\subsection{Standards and reagents}

The analytes in this study included five polycyclic musks and two nitro musks, three cyclic siloxanes and 13 linear siloxanes (Table S1). NMs (MK and MX), PCMs including HHCB (Galaxolide $\left.{ }^{\circledR}\right)$, AHTN (Tonalide $\left.{ }^{\circledR}\right)$, ADBI

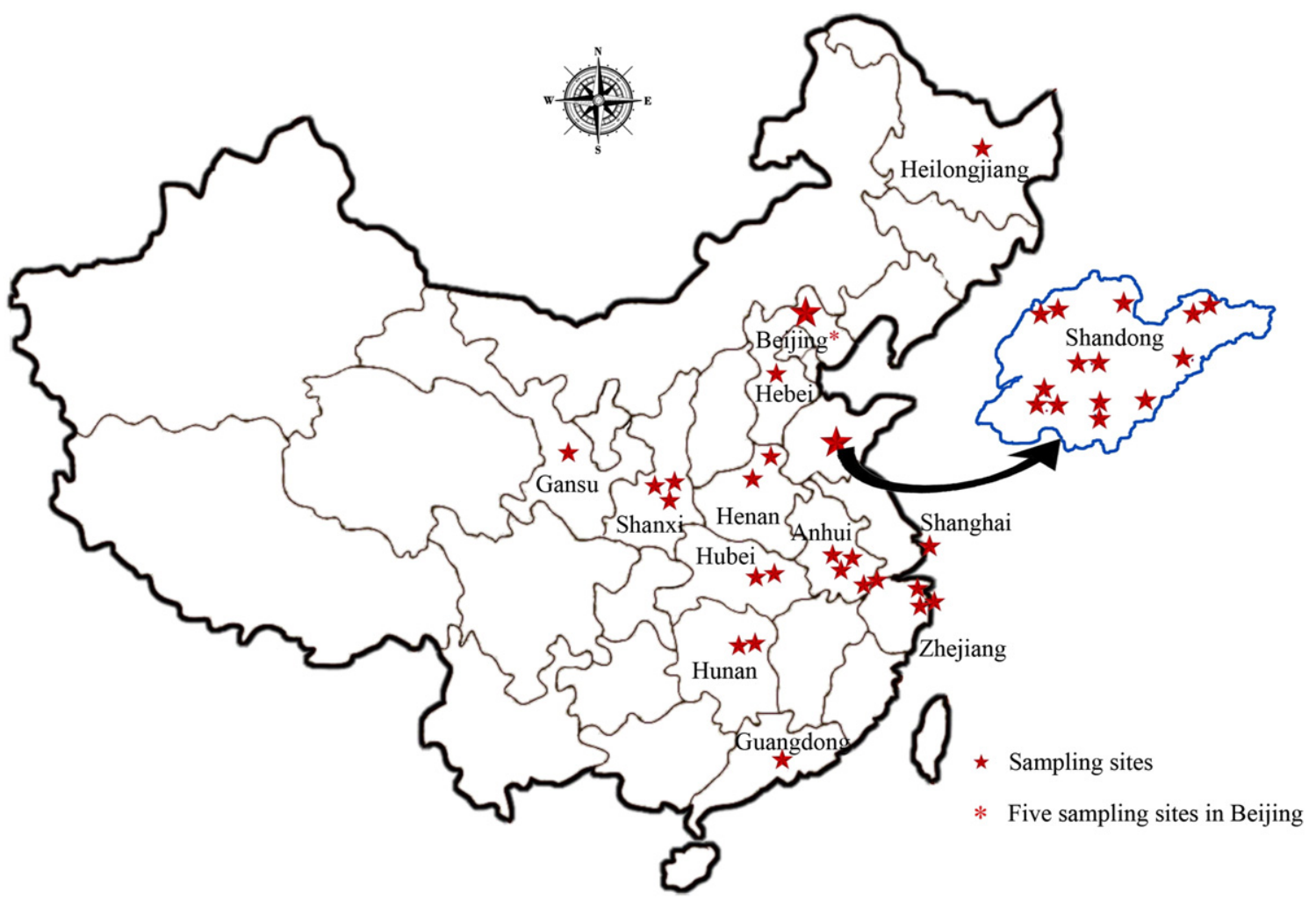

Fig. 1. Sampling locations of municipal sewage sludge samples in China. 
Table 1

Details of selected wastewater treatment plants.

\begin{tabular}{|c|c|c|c|c|c|c|c|c|}
\hline Sequence & Province & City & WWTPs & Treatment techniques & Sewage source & Treatment capacity $\left(10^{4} \mathrm{~m}^{3} / \mathrm{d}\right)$ & Population $\left(10^{4}\right)$ & TOC (\%) \\
\hline 1 & Beijing & Beijing & $\mathrm{BJ}-1$ & $\mathrm{AO}$ & Dom/ind & 10 & 40 & 39 \\
\hline 2 & & & $\mathrm{BJ}-2$ & $\mathrm{AAO}$ & Dom/ind & 100 & 240 & 39.1 \\
\hline 3 & & & $\mathrm{BJ}-3$ & OD & Dom/ind & 108 & 48 & 37 \\
\hline 4 & & & BJ-4 & AAO & Dom & 40 & 81.4 & 35.5 \\
\hline 5 & & & BJ-5 & SBR & Dom & 8 & 18 & 40.6 \\
\hline 6 & Hubei & Wuhan & WH-1 & $\mathrm{AO}$ & Dom & 24 & 63 & 7.1 \\
\hline 7 & & & WH-2 & AAO & Dom/ind & 15 & 30 & 13.6 \\
\hline 8 & Gansu & Lanzhou & $\mathrm{LZ}$ & $\mathrm{AO}$ & Dom/ind & 16 & 80 & 40.2 \\
\hline 9 & Hebei & Baoding & $\mathrm{BD}$ & AO & Dom/ind & 16 & 30 & 16.5 \\
\hline 10 & Heilongjiang & Jiamusi & JMS & OD & Dom/ind & 20 & 20 & 35.5 \\
\hline 11 & Shanghai & Shanghai & $\mathrm{SH}$ & SBR & Dom/ind & 6 & 20 & 45 \\
\hline 12 & Guangdong & Zhongshan & ZS & OD & Dom/ind & 10 & 25 & 28.8 \\
\hline 13 & Shangdong & Dongying & DY & $\mathrm{AO}$ & Dom/ind & 5 & 10 & 30.7 \\
\hline 14 & & Rizhao & $\mathrm{RZ}$ & SBR & Dom/ind & 5 & 10 & 34 \\
\hline 15 & & Yantai & YT-1 & $\mathrm{AAO}$ & Dom/ind & 4 & 21 & 36.6 \\
\hline 16 & & & YT-2 & $\mathrm{AAO}$ & Dom/ind & 2 & 9 & 37.4 \\
\hline 17 & & Qingdao & QD-1 & AAO & Dom/ind & 10 & 30 & 35.8 \\
\hline 18 & & & QD-2 & OD & Dom/ind & 4 & 10 & 34.8 \\
\hline 19 & & Linyi & LY-1 & OD & Dom/ind & 15 & 50 & 35.9 \\
\hline 20 & & & LY-2 & $\mathrm{AAO}$ & Dom/ind & 5 & 42 & 29.6 \\
\hline 21 & & Laiwu & LW-1 & $\mathrm{AO}$ & Dom/ind & 4 & 10 & 20 \\
\hline 22 & & & LW-2 & $\mathrm{AO}$ & Dom & 1.5 & 8 & 20.2 \\
\hline 23 & & Dezhou & DZ-1 & $\mathrm{AO}$ & Dom/ind & 2 & 10 & 10.4 \\
\hline 24 & & & DZ-2 & AAO & Dom & 2 & 10 & 16.2 \\
\hline 25 & & Jining & JN-1 & $\mathrm{AAO}$ & Dom & 20 & 40 & 13.9 \\
\hline 26 & & & $\mathrm{JN}-2$ & AAO & Dom/ind & 4 & 20 & 17.2 \\
\hline 27 & & & JN-3 & OD & Dom/ind & 3 & 25 & 22.5 \\
\hline 28 & Hunan & Changsha & CS-1 & $\mathrm{AO}$ & Dom/ind & 18 & 50 & 7.8 \\
\hline 29 & & & CS-2 & AAO & Dom/ind & 16 & 47.5 & 13.8 \\
\hline 30 & Henan & Puyang & PY & OD & Dom/ind & 10 & 22 & 27 \\
\hline 31 & & Xinxiang & $\mathrm{XX}$ & $\mathrm{AO}$ & Dom & 15 & 20 & 34.4 \\
\hline 32 & Shanxi & Xi'an & XA-1 & OD & Dom/ind & 8 & 15 & 29.9 \\
\hline 33 & & & $\mathrm{XA}-2$ & AAO & Dom/ind & 25 & 50 & 39.1 \\
\hline 34 & & Xianyang & $\mathrm{XY}$ & OD & Dom/ind & 10 & 15 & 36 \\
\hline 35 & Anhui & Hefei & HF-1 & OD & Dom/ind & 18 & 30.4 & 28.1 \\
\hline 36 & & & HF-2 & OD & Dom/ind & 30 & 30 & 32.4 \\
\hline 37 & & & HF-3 & SBR & Dom & 5.5 & 17 & 25.8 \\
\hline 38 & Zhejiang & Ningbo & NB-1 & $\mathrm{AO}$ & Dom/ind & 3 & 5 & 16.8 \\
\hline 39 & & & NB-2 & $\mathrm{AO}$ & Ind & - & - & - \\
\hline 40 & & & NB-3 & $\mathrm{AAO}$ & Dom & 12 & 15 & 22.6 \\
\hline 41 & & Hangzhou & HZ-1 & AAO & Dom/ind & 115 & 250 & 24.9 \\
\hline 42 & & & $\mathrm{HZ}-2$ & AAO & Dom/ind & 40 & 100 & 21.7 \\
\hline
\end{tabular}

(Celestolide ${ }^{\circledR}$ ), AHMI (Phantolide $\left.{ }^{\circledR}\right)$, ATII (Traseolide ${ }^{\circledR}$ ) standards and the internal standard $\mathrm{HCB}-{ }^{13} \mathrm{C}_{6}$ were all obtained from Dr. Ehrenstorfer (Augsburg, Germany). Surrogate standard $\mathrm{d}_{10}$-fluoranthen was purchased from Supeclo (Bellefonte, PA, USA). Cyclic siloxane standards (purity > 98\%) including D4, D5 and dodecamethylcyclohexasiloxane (D6), linear siloxane standards (purity > 98\%) including octamethyltrisiloxane (L3), decamethyltetrasiloxan (L4), polydimethylsiloxane mixture (PDMS, L5-L16), and tetrakis (trimethylsilyoxy) silane $\left(\mathrm{M}_{4} \mathrm{Q}\right.$ purity $>97 \%$ ) were purchased from Sigma-Aldrich (St. Louis, MO, USA). Solvents, including dichloromethane (DCM), n-hexane (HEX) and ethyl acetate and acetone, were all of high-performance liquid chromatography (HPLC) grade. Anhydrous sodium sulfate $\left(\mathrm{Na}_{2} \mathrm{SO}_{4}\right)$ and silica gel (100-200 mesh) were baked at $450{ }^{\circ} \mathrm{C}$ for $4 \mathrm{~h}$ prior to use.

\subsection{Sample pre-treatment and quantitative analysis}

\subsubsection{Pretreatment for SMs}

The sample pretreatment procedure is similar to previously reported methods (Hu et al., 2011). Freeze-dried sludge samples were sieved through a stainless steel 50 -mesh $(0.3 \mathrm{~mm})$ sieve, after which the weighed sample $(0.1 \mathrm{~g})$ was spiked with $20 \mu \mathrm{L}$ of $\mathrm{d}_{10}$-fluoranthen $(100 \mu \mathrm{g} / \mathrm{L}$, Surrogate standard), and then mixed with $4 \mathrm{~g}$ of activated silica (100-200 mesh) and $28 \mathrm{~g}$ anhydrous sodium sulfate. The mixture was placed into a $34 \mathrm{~mL}$ stainless steel extraction cell. The cells were extracted with HEX/DCM $(1: 1, \mathrm{v} / \mathrm{v})$ under conditions of $60{ }^{\circ} \mathrm{C}$ and
1500 psi within two static extraction cycles (15 min of each) using an accelerated solvent extractor (ASE 350, Dionex Corporation). All extracts were concentrated to $2 \mathrm{~mL}$ by rotary evaporation and loaded onto a chromatography column (packed with glass wool, $3 \mathrm{~g}$ activated silica gel and $0.5 \mathrm{~g}$ anhydrous $\mathrm{Na}_{2} \mathrm{SO}_{4}$ consecutively), which was preconditioned by $8 \mathrm{~mL}$ HEX. All analytes were subsequently eluted with $5 \mathrm{~mL}$ HEX, $15 \mathrm{~mL}$ HEX/DCM (2:1), $15 \mathrm{~mL}$ HEX/DCM (1:2) and $20 \mathrm{~mL}$ HEX/DCM (1:3). The eluant was concentrated, and the solvent was exchanged with HEX into $1 \mathrm{~mL}$. Finally, $100 \mathrm{ng}$ internal standard $\left(\mathrm{HCB}-{ }^{13} \mathrm{C}_{6}\right.$ ) was added before instrumental analysis.

\subsubsection{Pretreatment for siloxanes}

An ultrasound-assisted extraction procedure was employed based on a previously described method with minor modifications (Xu et al., 2012a). Briefly, $0.1 \mathrm{~g}$ of the sieved sample was spiked with $100 \mu \mathrm{L}$ of $1 \mathrm{mg} / \mathrm{L} \mathrm{M} \mathrm{Q}$ solution as the internal standard. The spiked sample was extracted with $10 \mathrm{~mL}$ of ethyl acetate/HEX mixture (1:1) for $15 \mathrm{~min}$ in an ultrasonic bath, and the mixture was then centrifuged at $3500 \mathrm{rpm}$ for $10 \mathrm{~min}$. The collected supernatant was transferred to a new glass tube. The extraction procedure was repeated three times. The total extract was concentrated to $2 \mathrm{~mL}$ under a gentle stream of $\mathrm{N}_{2}$ and then purified by passing through a cartridge packed with $1.0 \mathrm{~g}$ anhydrous $\mathrm{Na}_{2} \mathrm{SO}_{4}$. Finally, the eluent was concentrated to $1 \mathrm{~mL}$ under a gentle stream of $\mathrm{N}_{2}$ before GC-MS analysis. 


\subsubsection{Instrument analysis}

All target compounds were determined using a GC/MS system (Agilent 7890A GC/5975C MSD) with an electron-impact (EI) ionization source. The target analytes were separated by a $5 \%$ phenyl methyl siloxane capillary column (HP-5 ms; $30 \mathrm{~m} \times 0.25 \mathrm{~mm}$ i.d. $\times 0.25 \mu \mathrm{m}$ ).

The temperature of the GC injector port (splitless mode) was set as follows: $250{ }^{\circ} \mathrm{C}$ for SMs; $200{ }^{\circ} \mathrm{C}$ for L3, L4 and D4-D6; $300{ }^{\circ} \mathrm{C}$ for L5L16, and $230{ }^{\circ} \mathrm{C}$ for the ionization source (except for L5-L16: $280{ }^{\circ} \mathrm{C}$ ). Table S1 summarized mass-to-charge ratios of ions used to monitor the signal of each compound.

\subsection{Quality assurance and quality control (QA/QC)}

Due to the extensive use of SMs and siloxanes in consumer and laboratory products and their broad distribution in environment, a series of precautions were taken during the sample collection, pretreatment and analysis: (1) all participants in sample extraction and analysis refrained from using PCPs (perfumes, cosmetic products and hand cleaners), and powder free nitrile gloves were used throughout the experiment; (2) sampling or storage device during field collection was made of non-silica gel materials, and all glassware was rinsed with acetone before use; (3) due to the volatility of cyclic siloxanes, the mass losses of targets during freeze-drying process were also investigated, and the results showed that the recoveries of target compounds were more than $96 \%$. Besides, the blank samples showed that there was little cross-contamination during freeze-drying process (the levels of targets in blank samples were all below LOQ); (4) during GC/MS analysis (especially for D4, D5 and D6), low injector port temperature $\left(200{ }^{\circ} \mathrm{C}\right)$ and low-bleed capillary columns (HP-5MS) were selected to minimize targets bleeding from inlet septum and capillary columns.

Good recoveries were found for the SMs (55\%-107\%) and siloxanes (69\%-104\%) in matrix spiked samples. Levels of targets in procedural blanks were $1.3-2.8 \mathrm{ng} / \mathrm{g}$ for HHCB and AHTN, and 1.0-1.7 ng/g for (D4, D5 and D6). Procedural blanks of every batch were subtracted during the quantification of concentration in sludge samples. For these above-mentioned compounds, limit of quantitation (LOQ) was determined as 10 times the standard deviation of the laboratory blank signals $(\mathrm{n}=7)$. For compounds not detected in procedural blanks, the limit of detection (LOD) and LOQ were determined based on a signal-to-noise ratio of 3 and 10. LOQs ranged from 0.4 to $2.2 \mathrm{ng} / \mathrm{g}$ for SMs and siloxanes. The detailed materials are listed in Table S1.

\subsection{Data analysis}

\subsubsection{Statistical analyses}

Statistical analyses were performed using the statistical software SPSS 18.0. Pearson correlation analysis was used to assess the correlations among either the seven SMs or the 17 siloxanes in sludge samples. Kruskal-Wallis test and multiple linear regressions were employed to assess the impact of nonparametric and parametric variables on target concentrations in sludge samples, respectively. For all comparisons, $p<0.05$ was considered significant.

\subsubsection{Ecotoxicological risk assessment}

Risk quotient (RQ) values were utilized for ecotoxicological risk assessment in digested-sludge amended soil, which are expressed as Eq. (1):

$\mathrm{RQ}=\frac{\text { PECsoil }}{\text { PNECsoil }}$

where PNEC $_{\text {soil }}$ is defined as the predicted no observed effect concentration on organisms and often derived from NOEC (no observed effect concentration). $\mathrm{PEC}_{\text {soil }}$ values are estimated as the concentration of pollutant in soil since one year after sludge-dose application. In general,
$\mathrm{RQ} \geq 1$ means a high risk; $0.1 \leq \mathrm{RQ}<1$ represents a medium risk; and $0.01 \leq \mathrm{RQ}<0.1$ indicates a low risk (Sánchez-Bayo et al., 2002).

The PNEC $_{\text {soil }}$ levels were $0.28 \mathrm{mg} / \mathrm{kg}$ wet weight ( ww) for AHTN and HHCB (HERA, 2004). An indicative PNEC soil about D5 has been estimated as $0.15 \mathrm{mg} / \mathrm{kg}$ ww according to previous study (Brooke et al., 2009). PNEC $_{\text {soil }}$ about D4 was assumed as $0.15 \mathrm{mg} / \mathrm{kg}$ ww due to the long-term exposure of a similar level of toxicity in D4 and D5.

$\mathrm{PEC}_{\text {soil }}$ values were measured via Eq. (2) according to the European Commission Technical Guidance Document on Risk Assessment EUR 20418 EN/2 (Arvaniti et al., 2012):

$\mathrm{PEC}_{\text {soil }}=\frac{\mathrm{C}_{\text {sludge }} \times \mathrm{APPL}_{\text {sludge }}}{\mathrm{DEPTH}_{\text {soil }} \times \mathrm{RHO}_{\text {soil }}}$

where $\mathrm{C}_{\text {sludge }}(\mathrm{g} / \mathrm{kg} \mathrm{dw})$ is the detected concentration of the target compound in digested sludge; $\mathrm{APPL}_{\text {sludge }}$ is the application rate of dry sludge onto agricultural soils (usually $0.5 \mathrm{~kg} / \mathrm{m}^{2}$ year); $\mathrm{DEPTH}_{\text {soil }}$ is the mixing depth (usually $0.20 \mathrm{~m}$ for agricultural soils); and $\mathrm{RHO}_{\text {soil }}$ is the bulk density of wet soil (usually $1.5 \times 10^{3} \mathrm{~kg} / \mathrm{m}^{3}$ for agricultural soils).

\section{Results and discussion}

\subsection{Concentrations and composition profiles of SMs in sludge}

Concentrations of the total SMs in 42 sludge samples were in the range of $47.3 \mathrm{ng} / \mathrm{g}$ to $68.2 \mu \mathrm{g} / \mathrm{g} \mathrm{dw}$ (mean: $5.52 \mu \mathrm{g} / \mathrm{g}$ ) (Fig. 2) The detection frequencies (DFs) of target analytes were distinct: HHCB (95\%), AHTN (98\%), ATII (38\%), ADBI (29\%), AHMI (19\%), MK (29\%) and MX (14\%). Spearman's correlation analysis showed strong correlations ( $p<0.01$ ) among PCMs (except for AHMI), as well as between PCMs and NMs (Table 2), which could suggest common sources and similar environmental fates of SMs.

We found that the composition profiles of SMs in sludge were similar in spite of different sewage sources and different districts of the WWTPs (Fig. 3a and Table 2). HHCB (63.8\%) and AHTN (31.7\%) were the predominant SMs in these sludge samples. This result agreed with a previous report showed that HHCB and AHTN represent approximately $90-95 \%$ of the SMs market globally, and the percentages of HHCB and AHTN were high in personal care and sanitation products (Upadhyay et al., 2011). In this study, concentrations of HHCB and AHTN varied in sludge samples from different WWTPs, ranging from $<$ LOQ to 41.4 (mean: $3.52 \mu \mathrm{g} / \mathrm{g}$ ) and <LOQ to $22.0 \mu \mathrm{g} / \mathrm{g}$ dw (mean: $1.75 \mu \mathrm{g} / \mathrm{g}$ ), respectively. The mean concentrations of HHCB and AHTN in this study were at the same levels as those from one previous study, which reported that the values of HHCB and AHTN in sludge from some WWTPs in Guangdong Province of China were 2.49 (0.270-8.42) and $1.99 \mu \mathrm{g} / \mathrm{g}(0.524-4.50 \mu \mathrm{g} / \mathrm{g} \mathrm{dw})$, respectively (Zeng et al., 2012). However, these mean levels were lower than those from Korea (31.2 for HHCB and $9.56 \mu \mathrm{g} / \mathrm{g}$ for AHTN), New York State (88.6 for HHCB and $12.6 \mu \mathrm{g} / \mathrm{g}$ for AHTN) and Hong Kong (27.1 for HHCB and $5.85 \mu \mathrm{g} / \mathrm{g}$ for AHTN) (Guo et al., 2010; Reiner et al., 2007; Shek et al., 2008). The large variability in concentrations might be attributed to different consumption patterns of PCMs in fragrance products in different areas and countries.

NMs contributed little to the total SMs. Concerns over the toxicity and bioaccumulation of NMs lead to restrictions on their appliance in cosmetics. However, they were still added in many cheap consumer products, leading to their presence in environmental samples and biota (Raab et al., 2008; Smyth et al., 2008). Compared with one previous study, which reported that the mean concentrations of MX (DF: $80 \%$ ) and MK (DF: 90\%) were 10.4 and $46.3 \mathrm{ng} / \mathrm{g}$ in sludge from Guangdong Province of China (Zeng et al., 2012), while these two compounds in our study had lower DFs (14\% for MX and 29\% for MK) but higher mean concentrations exceeding LOQ (382 for MX and $359 \mathrm{ng} / \mathrm{g} \mathrm{dw}$ for MK). The maximum levels of MX $(0.362 \mu \mathrm{g} / \mathrm{g} \mathrm{dw})$ and MK $(2.54 \mu \mathrm{g} / \mathrm{g} \mathrm{dw})$ were found in sludge from the 2nd WWTP in 


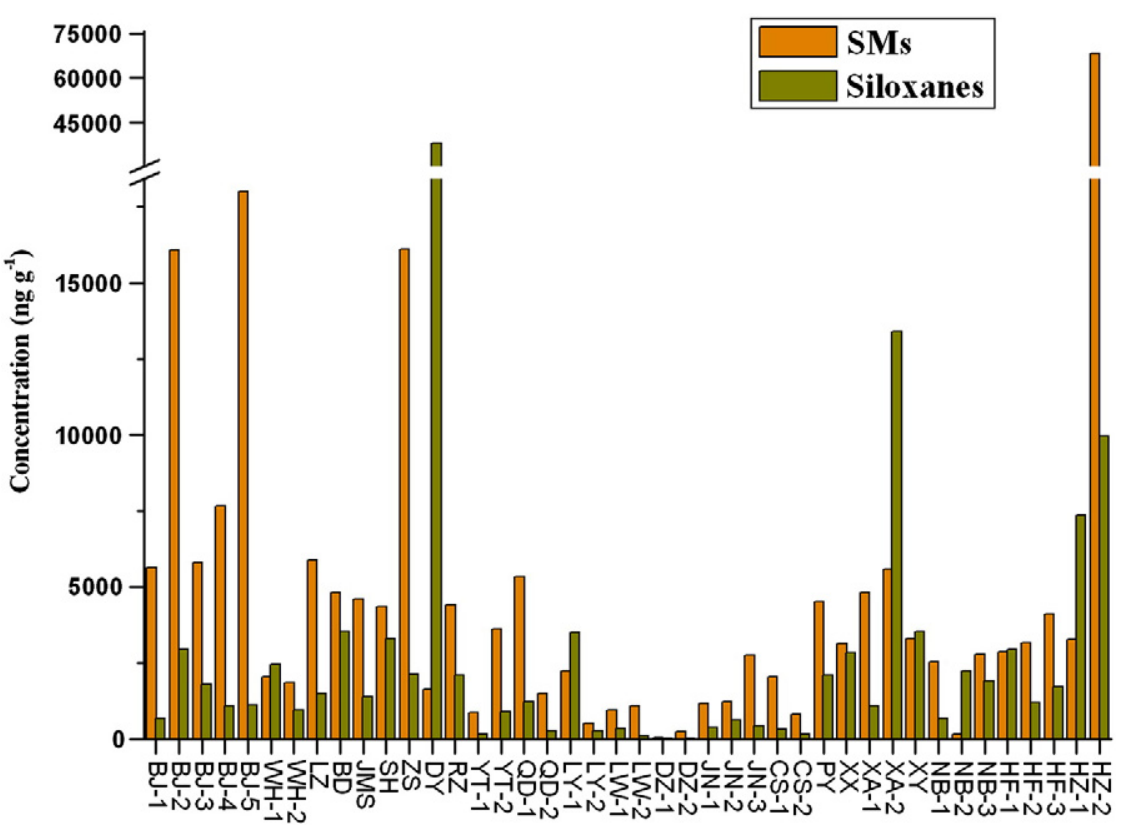

Fig. 2. Concentrations of $\sum S M s$ and $\sum$ siloxanes in sludge samples collected from 42 WWTPs.

Hangzhou city, which indicated the presence of point source pollution of NMs nearby this WWTP.

\subsection{Concentrations and composition profiles of siloxanes in sewage sludge}

The total concentration in sludge extended from $<$ LOQ to 36.0 (mean: 1.98) for cyclic (DF: 93\%-95\% for D4-D6), and $<$ LOQ to $13.0 \mu \mathrm{g} / \mathrm{g} \mathrm{dw}$ (mean: $0.937 \mu \mathrm{g} / \mathrm{g} \mathrm{dw}$ ) for linear (L3-L16) siloxanes, respectively (Fig. 3b). The mean concentration of the total cyclic siloxanes in sludge from this study was about one order of magnitude lower than those in Nordic countries $(26.0 \mu \mathrm{g} / \mathrm{g}$ ) and Greece $(20.2 \mu \mathrm{g} / \mathrm{g}$ ) (Bletsou et al., 2013; Kaj et al., 2005). Previous studies mainly focus on the occurrence of cyclic siloxanes in sludge, whereas studies on linear siloxanes were scarce (Wang et al., 2012; Whelan, 2013). The mean value of $\sum \mathrm{L} 4-\mathrm{L} 16(0.937 \mu \mathrm{g} / \mathrm{g})$ in 42 sludge samples was lower than that detected from Greece ( $\sum$ L3-L14, $53.9 \mu \mathrm{g} / \mathrm{g}$ ) (Bletsou et al., 2013). Different consumption quantities of siloxanes among these countries or regions might explain the remarkable variance of siloxanes levels in sludge. In addition, the samples in this study were anaerobic digested sludge. Losses caused by the volatilization and degradation of siloxanes during anaerobic digestion should be the other reason for lower concentrations of siloxanes in studied sludge (Brooke et al., 2009; Dewil et al., 2006).

Generally, the cyclic siloxanes (D4-D6) had (68\%) dominant concentrations in total siloxanes in this study. This result was inconsistent with the previous study which reported that the total concentrations of linear siloxanes (L3-L14) were roughly twice higher than those of cyclic siloxanes (D3-D7) in sludge from Greece (Bletsou et al., 2013). Generally speaking, cyclic siloxanes are primarily used in daily commodities and health care products, while linear siloxanes are widely used in industrial products (Zhang et al., 2011). In this study, higher concentrations of cyclic siloxanes than linear compounds in sludge might be caused by the dominance of domestic sewage in the studied WWTPs.

The average proportions in the total cyclic siloxanes were $45 \%, 34 \%$ and $21 \%$ for D4, D5 and D6, respectively (Fig. 3b), which indicated that D4 was the major cyclic siloxane. The observation in this work was discordant with some previous studies: Bletsou et al. (2013) reported that the average proportion of D4 in cyclic compounds (D4-D6) was only $0.54 \%$ in sludge, and the other study from Spain showed that the shares of D4 were 20\% (Companioni-Damas et al., 2012). One significant cause might be that the production of D4 has been limited in many developed countries due to its estrogenic activity (information available in English at: http://www.ec.gc.ca/planp2-p2plan/default.asp?lang= En\&n $=51567$ C93-1), while there is no any restriction measure in China till now.

In this study, the median concentrations of linear siloxanes (L6-L16, excepted L11) increased with the $\mathrm{Si}-\mathrm{O}$ chain length $(p<0.05)$ (Fig. 3b). The total concentration of L11-L16 (DF $=81 \%-95 \%$ ) accounted for $84 \%$ of all the studied linear siloxanes, which might be because the adsorption capacities of linear siloxanes would increase with their $\mathrm{Si}-\mathrm{O}$ chains (Kaj et al., 2005).

Table 2

Spearman's rank correlations among SMs in 42 sludge samples.

\begin{tabular}{|c|c|c|c|c|c|c|c|c|c|}
\hline & HHCB & AHTN & ADBI & AHMI & ATII & MX & MK & Polymusks & Nitromusks \\
\hline НHCB & 1 & & & & & & & & \\
\hline AHTN & $0.996^{* *}$ & 1 & & & & & & & \\
\hline ADBI & $0.890^{* *}$ & $0.898^{* *}$ & 1 & & & & & & \\
\hline AHMI & 0.009 & -0.016 & 0.141 & 1 & & & & & \\
\hline ATII & $0.923^{* *}$ & $0.927^{* *}$ & $0.951^{* *}$ & -0.023 & 1 & & & & \\
\hline MX & -0.079 & -0.074 & 0.017 & 0.231 & -0.053 & 1 & & & \\
\hline MK & $0.886^{* *}$ & $0.902^{* *}$ & $0.942^{* *}$ & -0.019 & $0.957^{* *}$ & -0.008 & 1 & & \\
\hline Polymusks & $0.999^{* *}$ & $0.998^{* *}$ & $0.898^{* *}$ & 0.003 & $0.930^{* *}$ & -0.076 & $0.897^{* *}$ & 1 & \\
\hline Nitromusks & $0.863^{* *}$ & $0.879^{* *}$ & $0.934^{* *}$ & 0.018 & $0.938^{* *}$ & 0.153 & $0.987^{* *}$ & $0.874^{* *}$ & 1 \\
\hline
\end{tabular}

** Correlation is significant at the 0.01 level (2-tailed) 


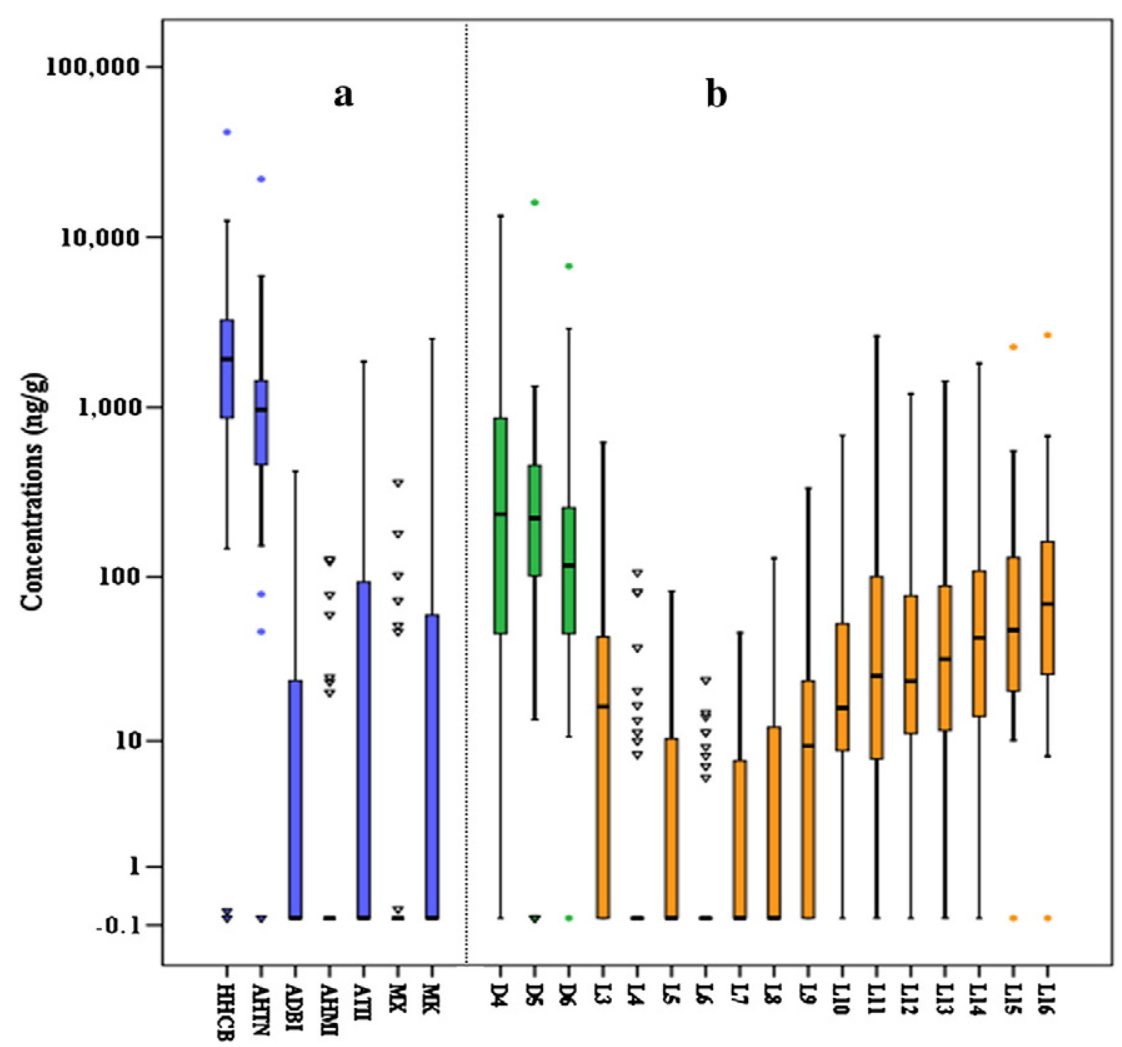

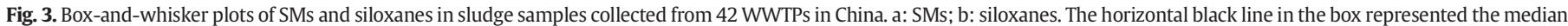

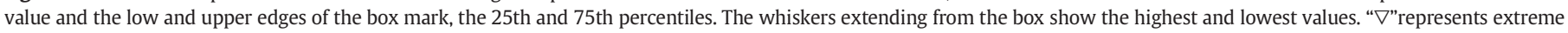

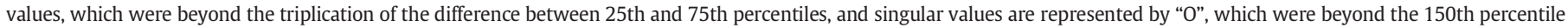
of the difference between 25 th and 75th percentiles.

\subsection{Distribution patterns of SMs and siloxanes in different WWTPS and influence factors}

The highest concentration of $\sum$ SMs $(68.2 \mu \mathrm{g} / \mathrm{g} \mathrm{dw})$ was detected in the sludge sample from the 2nd WWTP in Hangzhou city (Fig. 2). The lowest concentration $(47.3 \mathrm{ng} / \mathrm{g} \mathrm{dw})$ was observed in one WWTP which serves a water purification company in Dezhou city, followed by one WWTP primarily treating industrial wastewater, which serves an electroplating factory in Ningbo city (153 ng/g dw).

The highest concentrations of $\sum$ siloxanes $(38.0 \mu \mathrm{g} / \mathrm{g} \mathrm{dw})$ were found in the municipal WWTPs located in Dongying city (Fig. 2). The lowest one (22.1 ng/g dw) was detected in one WWTP, which was the same WWTP with the lowest concentration of $\sum$ SMs.

Levels of SMs and siloxanes considerably varied in sludge collected from different WWTPs in this study. In order to investigate potential factors affecting target compound levels in sewage sludge, we examined related information about WWTPs, including the TOC of sludge, sources of sewage [domestic $(n=9)$, industrial $(n=1)$ and combined $(\mathrm{n}=32)$ ] and the operational conditions of WWTPs (treatment technique, treatment capacity and serving population) (Table 1 ).

\subsubsection{SMs}

Using the nonparametric Kruskal-Wallis Test, we assessed the variation of SM concentrations in sludge samples grouped by two sewage sources of WWTPs, including domestic and the combined sewage sources [WWTP serving industrial source was excluded for too limited sample $(n=1)]$. The test showed that SM concentrations in sludge had no significant differences $(p>0.05)$ between two types of WWTPs (Table S2). Meanwhile, the SM concentration $(0.153 \mu \mathrm{g} / \mathrm{g} \mathrm{dw})$ in sludge from WWTP treating industrial sewage was an order of magnitude lower than the those from other two types of WWTPs (mean: 5.48 for domestic and $3.68 \mu \mathrm{g} / \mathrm{g}$ dw for the combined). A previous study reported that SMs were mainly used as fragrances in daily life and $77 \%$ of them would be drained into the sewer system (Reiner et al., 2007). Therefore, our results indicated that through afflux of industrial wastewater, domestic wastewater might be the primary source in these WWTPs with combined sewage. In addition, we found that the mean concentrations of $\sum$ SMs in sludge samples typed by four treatment processes were within the same order of magnitude: 7.69 for AAO, 4.78 for OD, 7.89 for SBR and $2.91 \mu \mathrm{g} / \mathrm{g} d w$ for AO. Furthermore, the Kruskal-Wallis vales $(p>0.05)$ showed no significant differences of their sludge concentrations among these four groups, showing that the treatment processes in the studied WWTPs had no significant effect on the SM levels in sludge.

We also examined the relationships between SM concentrations in sludge samples and parameter variables about WWTPs (TOC of the sludge, treatment capacity and serving population) by multivariate linear regression analysis (Table 3 ). In the multivariate models, strong positive correlations were found between SM concentrations and the serving population (standardized coefficient $0.413, p=0.034$ ) as well as TOC (standardized coefficient $0.489, p=0.001$ ). The present results might be attributed to the fact that WWTPs serving larger population are commonly situated in larger cities, where people might use more fragrance products. In addition, the lipophilicity of SMs might result in the significant influence of TOC of the sludge on SM levels.

\subsubsection{Siloxanes}

Similar with SMs, the nonparametric tests showed that siloxane concentrations in sludge had no significant differences $(p>0.05)$ between two groups of WWTPs with different sewage sources. According to the above result coupled with the dominance of cyclic siloxanes in sludge (68\%, Section 3.2), which were mainly used in personal care product, we also could deduce that combined sewage in the studied WWTPs might be mainly from domestic wastewater. 
Table 3

Coefficients from multivariate regression of total-SMs, cyclic siloxanes and linear siloxanes.

\begin{tabular}{|c|c|c|c|c|c|c|}
\hline Outcome & Independent variate & Coef & Std. err. & Standardized coef & $\mathrm{t}$ & $p$ \\
\hline \multirow[t]{3}{*}{ Total-SMs } & TOC & 173.429 & 45.887 & 0.489 & 3.779 & $0.001^{\text {** }}$ \\
\hline & Treatment capacity & -25.415 & 47.077 & -0.100 & -0.540 & 0.593 \\
\hline & Service population & 43.669 & 19.800 & 0.413 & 2.205 & $0.034^{*}$ \\
\hline \multirow[t]{3}{*}{ Cyclic siloxanes } & TOC & 21.768 & 16.341 & 0.160 & 1.332 & 0.191 \\
\hline & Treatment capacity & 91.672 & 15.757 & 1.023 & 5.818 & $0.000^{* *}$ \\
\hline & Service population & -3.182 & 8.491 & -0.046 & -0.375 & 0.710 \\
\hline \multirow[t]{3}{*}{ Linear siloxanes } & TOC & 36.374 & 11.961 & 0.461 & 3.041 & $0.004^{* *}$ \\
\hline & Treatment capacity & 2.896 & 11.534 & 0.056 & 0.251 & 0.803 \\
\hline & Service population & 1.145 & 4.913 & 0.052 & 0.233 & 0.817 \\
\hline
\end{tabular}

* Statistically significant $(p<0.05)$

** Statistically significant $(p<0.01)$

The mean concentrations of total siloxanes in sludge samples grouped by four treatment processes were within the same order of magnitude: 4.39 for AO, 2.75 for AAO, 2.06 for SBR and $1.80 \mu \mathrm{g} / \mathrm{g} \mathrm{dw}$ for OD, respectively. In addition, no significant difference $(p>0.05)$ of siloxane concentrations was found among those four groups. These results suggested that siloxane concentrations in sludge were not affected by these four treatment techniques, which was consistent with the SMs.

Generally, cyclic siloxanes are primarily used in daily life, while linear siloxanes mainly in industry. In our study, the main source of sewage in studied WWTPs was identified as domestic wastewater. These reasons could explain the result that cyclic but not linear siloxanes had the positive associations (standardized coefficient 1.203, $p=0.000$ ) with treatment capacity (Table 3 ). The correlations between linear siloxanes and TOC in sludge samples were statistically significant (standardized coefficient $0.461, p=0.004$ ). However, no similar result
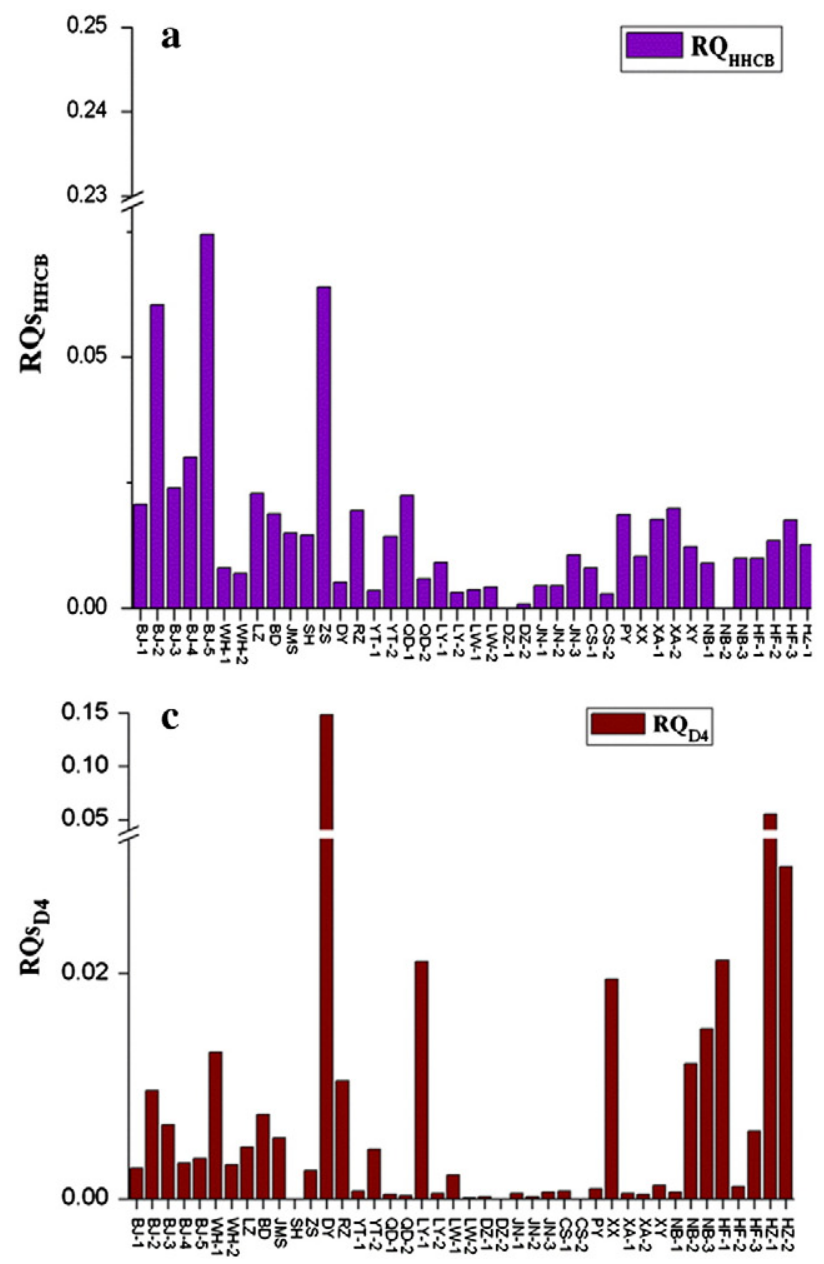

was observed for cyclic siloxanes. These results indicated that TOC of the sludge would have a greater impact on linear siloxanes than cyclic siloxanes, which might be because the linear siloxanes could bind to sludge with a higher affinity than cyclic siloxanes (Bletsou et al., 2013; Zhang et al., 2011).

\subsection{Risk assessment}

In the present study, SMs and siloxanes were detected in all digested sludge samples with high DFs and concentrations. Therefore, it was necessary to assess the ecological risk of the recycled sewage sludge to soil compartments. In this study, HHCB, AHTN, D4 and D5 were selected as the representative compounds.

The results showed that all of RQs were lower than 0.1 except for two RQs about HHCB (0.247) and AHTN (0.131) in the 2nd WWTP of
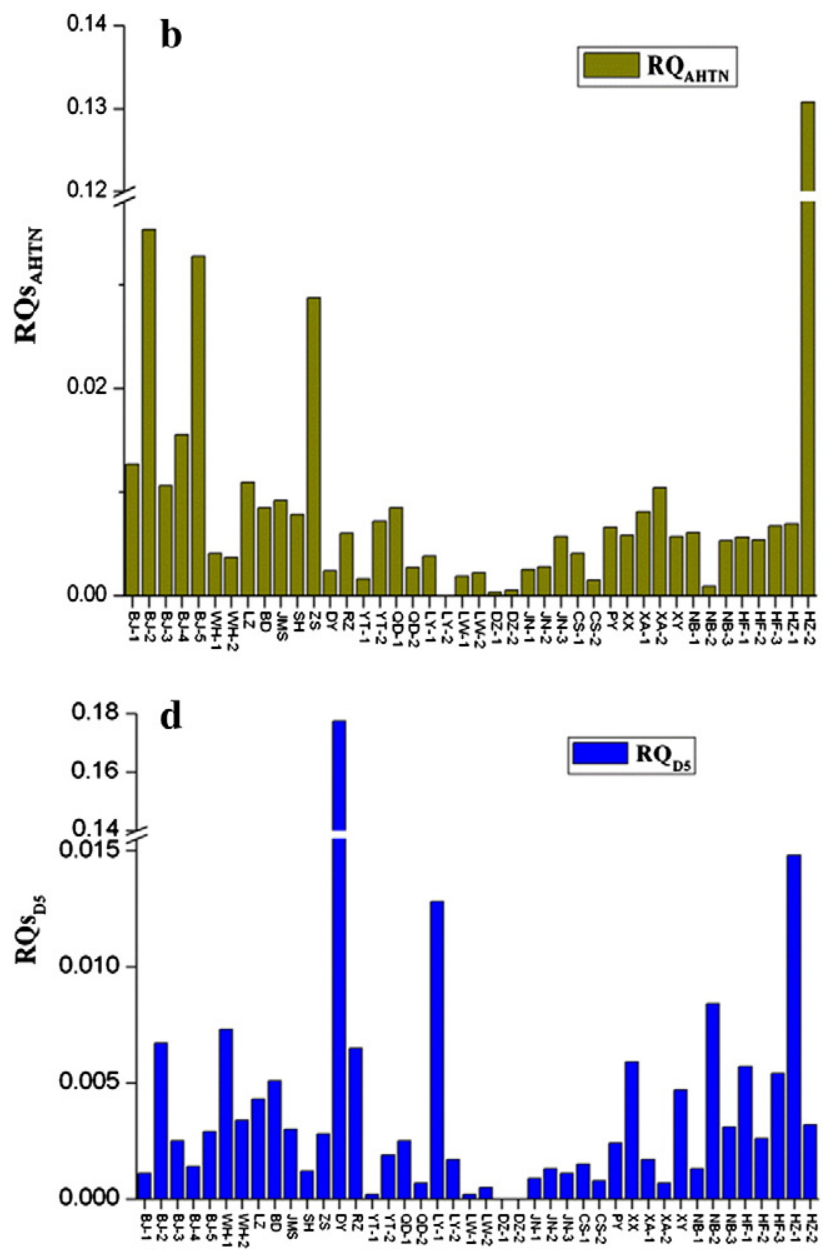

Fig. 4. RQs about HHCB, AHTN, D4 and D5 calculated from sludge as bio-soil. a: HHCB; b: AHTN; c: D4; d:D5. 
Hangzhou and two RQs about D4 (0.148) and D5 (0.178) in the WWTP of Dongying city. In particular, most of RQs (17/42 for HHCB, 33/42 for AHTN, 32/42 for D4 and 39/42 for D5) were lower than 0.01 (Fig. 4a-d). Taken together, only four RQs were in the range of $0.1 \leq \mathrm{RQ}<1$, indicating a medium risk when the sludge in these WWTPs is recycled to farm. However, to sum up, these four studied compounds might present very low risk to the soil compartment from biosolids land application.

\section{Conclusions}

In this study, we investigated the levels and distribution patterns of SMs (5 PCMs and 2 NMs) and siloxanes ( 3 cyclic siloxanes and 14 linear siloxanes) in sewage sludge samples collected from 42 WWTPs in 23 cities of China. SMs were detected in all of the sludge samples at concentrations ranging from $47.3 \mathrm{ng} / \mathrm{g}$ to $68.2 \mu \mathrm{g} / \mathrm{g} \mathrm{dw}$. The two main components, HHCB and AHTN, accounted for $95.5 \%$ of $\sum$ SMs. Very similar composition profiles of SMs were found in sludge samples from the all studied WWTPs, revealing their similar consumption models and extensive pollution in China. Cyclic siloxane concentrations $(<\mathrm{LOQ}-36.1 \mu \mathrm{g} / \mathrm{g} \mathrm{dw})$ accounted for $68 \%$ of the total siloxanes, and on average, they were $>2$ folds higher than linear siloxanes $(<\mathrm{LOQ}-$ $13.2 \mu \mathrm{g} / \mathrm{g} \mathrm{dw}$ ), suggesting that domestic sewage might account for significant proportions in 42 WWTPs. High concentrations and DFs of SMs and siloxanes in sewage sludge disclosed the wide-ranging pollution caused by the extensive usages of these pollutants in China. Moreover, the levels of SMs and siloxanes in sewage sludge were associated with the potential factors including TOC of the sludge, sewage composition, treatment capacity and serving population of the studied WWTPs. Also, risk assessments of the excess sludge applied as fertilizer in agriculture were performed and negligible effect was observed.

\section{Acknowledgments}

This work was supported by the National Key Basic Research Program of China (2014CB114402, 2009CB421605) and the National Natural Science Foundation of China (No. 41023005).

\section{Appendix A. Supplementary data}

Supplementary data to this article can be found online at http://dx. doi.org/10.1016/j.scitotenv.2013.12.124.

\section{References}

Available inhttp://www.ec.gc.ca/planp2-p2plan/default.asp?lang =En\&n=51567C93-1. Arvaniti OS, Ventouri EI, Stasinakis AS, Thomaidis NS. Occurrence of different classes of perfluorinated compounds in Greek wastewater treatment plants and determination of their solid-water distribution coefficients. J Hazard Mater 2012;239:24-31.

Bletsou A, Asimakopoulos AG, Stasinakis A, Thomaidis NS, Kannan K. Mass loading and fate of linear and cyclic siloxanes in a wastewater treatment plant in Greece. Environ Sci Technol 2013;47:1824-32.

Borga K, Fjeld E, Kierkegaard A, McLachlan MS. Food web accumulation of cyclic siloxanes in Lake Mjosa, Norway. Environ Sci Technol 2012;46:6347-54.

Brooke DN, Crookes MJ, Gray D, Robertson SEnvironmental Risk Assessment Report: Decamethylcyclopentasiloxane; 2009. [http://publications.environment-agency.gov. uk/PDF/SCHO0309BPQX-E-E.pdf].

Companioni-Damas EY, Santos FJ, Galceran MT. Analysis of linear and cyclic methylsiloxanes in sewage sludges and urban soils by concurrent solvent recondensation - large volume injection - gas chromatography-mass spectrometry. J Chromatogr A 2012;1268:150-6.

Dewil R, AppelS L, BaeyenS J. Energy use of biogas hampered by the presence of siloxanes. Energy Convers Manag 2006:47:1711-22.

Guo GH, Wu FC, He HP, Zhang RQ Li HX. Screening level ecological risk assessment for synthetic musks in surface water of Lake Taihu, China. Stoch Env Res Risk A 2012;27:111-9.

Guo R, Lee IS, Kim UJ, Oh JE. Occurrence of synthetic musks in Korean sewage sludges. Sci Total Environ 2010:408:1634-9.

Hanssen L, Warner NA, Braathen T, Odland JO, Lund E, Nieboer E, et al. Plasma concentrations of cyclic volatile methylsiloxanes (cVMS) in pregnant and postmenopausal Norwegian women and self-reported use of personal care products (PCPs). Environ Int 2013;51:82-7.
Heberer T. Occurrence, fate, and assessment of polycyclic musk residues in the aquatic environment of urban areas - a review. Acta Hydrochim Hydrobiol 2003;30:227-43.

HERA (Human and Environmental Risk Assessment on ingredients of household cleaning products). Polycyclic Musks AHTN (CAS 1506-02-1) and HHCB (CAS 1222-05-05). downloadable athttp://www.heraproject.com/RiskAssessment.cfm, 2004.

Horii Y, Kannan K. Survey of organosilicone compounds, including cyclic and linear siloxanes, in personal-care and household products. Arch Environ Contam Toxicol 2008;55(4):701-10.

Horii Y, Reiner JL, Loganathan BG, Senthil Kumar K, Sajwan K, Kannan K. Occurrence and fate of polycyclic musks in wastewater treatment plants in Kentucky and Georgia, USA. Chemosphere 2007:68:2011-20.

Hu Z, Shi Y, Cai Y. Concentrations, distribution, and bioaccumulation of synthetic musks in the Haihe River of China. Chemosphere 2011;84:1630-5.

Kaj L, Schlabach M, Andersson J, Palm Cousins A, Schmidbauer N, Brorström-Lundén E. Siloxanes in the Nordic Environment, 93; 2005 [http://www.imm.ki.se/Datavard/ PDF/B1643_siloxaner.pdf.].

Krogseth IS, Kierkegaard A, McLachlan MS, Breivik K, Hansen KM, Schlabach M. Occurrence and seasonality of cyclic volatile methyl siloxanes in arctic air. Environ Sci Technol 2013;47:502-9.

Kubwabo C, Fan X, Rasmussen PE, Wu F. Determination of synthetic musk compounds in indoor house dust by gas chromatography-ion trap mass spectrometry. Anal Bioanal Chem 2012;404:467-77.

Lu M, Wu XJ, Zeng DC, Liao Y. Distribution of PCDD/Fs and organometallic compounds in sewage sludge of wastewater treatment plants in China. Environ Pollut 2012;171: 78-84.

Lu Y, Yuan T, Wang W, Kannan K. Concentrations and assessment of exposure to siloxanes and synthetic musks in personal care products from China. Environ Pollut 2011a;159: 3522-8.

Lu Y, Yuan T, Yun SH, Wang WH, Kannan K. Occurrence of synthetic musks in indoor dust from China and implications for human exposure. Arch Environ Contam Toxicol 2011b;60:182-9.

Moon HB, Lee DH, Lee YS, Kannan K. Occurrence and accumulation patterns of polycyclic aromatic hydrocarbons and synthetic musk compounds in adipose tissues of Korean females. Chemosphere 2012;86:485-90.

Nakata $\mathrm{H}$, Sasaki $\mathrm{H}$, Takemura A, Yoshioka M, Tanabe S, Kannan K. Bioaccumulation, temporal trend, and geographical distribution of synthetic musks in the marine environment. Environ Sci Technol 2007;41:2216-22.

Parker WJ, Shi JC, Fendinger NJ, Monteith HD, Chandra G. Pilot plant study to assess the fate of two volatile methyl siloxane compounds during municipal wastewater treatment. Environ Toxicol Chem 1999;18:172-81.

Parrott JL, Alaee M, Wang D, Sverko E. Fathead minnow (Pimephales promelas) embryo to adult exposure to decamethylcyclopentasiloxane (D5). Chemosphere 2012. http: //dx.doi.org/10.1016/j.chemosphere.2012.10.053.

Raab U, Preiss U, Albrecht M, Shahin N, Parlar H, Fromme H. Concentrations of polybrominated diphenyl ethers, organochlorine compounds and nitro musks in mother's milk from Germany (Bavaria). Chemosphere 2008;72:87-94.

Reiner JL, Berset JD, Kannan K. Mass flow of polycyclic musks in two wastewater treatment plants. Arch Environ Contam Toxicol 2007;52:451-7.

Sánchez-Bayo F, Baskaran S, Kennedy IR. Ecological relative risk (EcoRR): another approach for risk assessment of pesticides in agriculture. Agr Ecosyst Environ 2002;91:37-57.

Sanchis J, Martinez E, Ginebreda A, Farre M, Barcelo D. Occurrence of linear and cyclic volatile methylsiloxanes in wastewater, surface water and sediments from Catalonia. Sci Total Environ 2013;443:530-8.

Schnell S, Martin-Skilton R, Fernandes D, Porte C. The interference of nitro- and polycyclic musks with endogenous and xenobiotic metabolizing enzymes in carp: an in vitro study. Environ Sci Technol 2009;43:9458-64.

Shek WM, Murphy MB, Lam JCW, Lam PKS. Synthetic polycyclic musks in Hong Kong sewage sludge. Chemosphere 2008;71:1241-50.

Smyth SA, Lishman LA, McBean EA, Kleywegt S, Yang JJ, Svoboda ML, et al. Seasonal occurrence and removal of polycyclic and nitro musks from wastewater treatment plants in Ontario, Canada. J Environ Eng Sci 2008;7:299-317.

Upadhyay N, Sun QY, Allen JO, Westerhoff P, Herckes P. Synthetic musk emissions from wastewater aeration basins. Water Res 2011;45:1071-8.

Wang DG, Norwood W, Alaee M, Byer JD, Brimble S. Review of recent advances in research on the toxicity, detection, occurrence and fate of cyclic volatile methyl siloxanes in the environment. Chemosphere 2012. http://dx.doi.org/10.1016/ j.chemosphere.2012.10.041.

Whelan MJ. Evaluating the fate and behaviour of cyclic volatile methyl siloxanes in two contrasting North American lakes using a multi-media model. Chemosphere 2013. http://dx.doi.org/10.1016/j.chemosphere.2012.12.048.

$\mathrm{Xu} \mathrm{L}$, Shi Y, Cai Y. Occurrence and fate of volatile siloxanes in a municipal wastewater treatment plant of Beijing, China. Water Res 2012b. http://dx.doi.org/10.1016/ j.watres.2012.10.046.

Xu L, Shi YL, Wang T, Dong ZR, Su WP, Cai YQ. Methyl siloxanes in environmental matrices around a siloxane production facility, and their distribution and elimination in plasma of exposed population. Environ Sci Technol 2012a;46:11718-26.

Zeng XY, Cao SX, Zhang DL, Gao ST, Yu ZQ, Li HR, et al. Levels and distribution of synthetic musks and polycyclic aromatic hydrocarbons in sludge collected from Guangdong Province. J Environ Sci Health 2012;47:389-97.

Zeng XY, Sheng GY, Xiong Y, Fu JM. Determination of polycyclic musks in sewage sludge from Guangdong, China using GC-EI-MS. Chemosphere 2005;60:817-23.

Zhang ZF, Qi H, Ren NQ Li YF, Gao DW, Kannan K. Survey of cyclic and linear siloxanes in sediment from the Songhua River and in sewage sludge from wastewater treatment plants, Northeastern China. Arch Environ Contam Toxicol 2011;60:204-11. 